\title{
Research of the Relationship between Defense Expenditure and Economic Operation Based on Unconstrained VAR Model
}

\author{
Kan Zhang ${ }^{\text {a }}$, Baoping Liu and Meng Wang \\ Naval Univ. of Engineering, Hubei Wuhan, 430033, China \\ a719273356@qq.com
}

Keywords: vector auto regression, civil military integration, crowding-out effect, spillover effect.

\begin{abstract}
Based on unstructured dynamic modeling theory, collected data samples 37 years to establish unconstrained VAR model to analyze operating rules among defense expenditure, economic growth and private consumption. Research showed that there was a long-term balanced relationship among three factors. Economic growth and private consumption had a significant positive effect on defense expenditure, although not defense expenditure on economic growth and private consumption have a "crowding-out effect", but overall defense expenditure was still present negative scale characteristics, "spillover effect" was not obvious, needed to further strengthen the civil-military integration, improve scientific prediction capability of defense expenditure.
\end{abstract}

\section{Introduction}

Defense expenditure reflected the economic characterization of construction level in the field of national defense, represented the basic trend of defense policy. As a non-productive expenditure, the relationship between defense expenditure and national economy operation had been the focus of research in the field of national defense economy. Generally speaking, the national economy operating state could be comprehensive measured by economic growth indicators and private consumer indicators. GDP indicator was usually chosen to represent economic growth indicators that reflected the whole national economic characteristics, belong to macroeconomic indicators; Residents average consumption level indicator was usually chosen to represent private consumer indicators that reflected individual characteristics of the national economy, belong to microeconomic indicators. This paper attempted to use empirical analysis to avoid the "spurious regression" phenomenon brought by the traditional linear regression analysis with unconstrained VAR model, by which studied the relationship among the three indicators, determined a reasonable level of defense expenditure to improve operational efficiency of the national economy.

\section{Literature Review}

A large number of domestic and foreign literature showed that there was no typical consistent conclusion between the defense expenditure and economic growth. One was the view of promotion theory. Benoit ${ }^{[1]}$ analyzed economic cross-section data from 44 countries, got the fundamental conclusion that defense expenditure played a significant role in promoting economic growth; Halicioglu ${ }^{[2]}$ placed Turkey, for example, further pointed out that defense expenditure and non-defense expenditure were all positively correlated to economic growth, and the latter more significant role. Another was the view of suppression theory. Lim $^{[3]}$ made the sample of developing countries, pointed out that defense expenditure would make some negative effects to economic growth; Starr ${ }^{[4]}$ supported the view of Lim, and further pointed out the reason of defense expenditure hindering economic growth is to produce inflation; Cuaresma ${ }^{[5]}$ and others on the US defense fees sampling data analysis, the increase in defense expenditure would make "crowding out" effect to economic growth. The third was the view of neutral theory. As Cappelen ${ }^{[6]}$ suggested that defense expenditure in OPEC member countries had two-sides influence, the increase in defense expenditure was in favor of the manufacturing but not foreign investment; Wolde-Rufael pointed out that only 
one-way Granger causality existed in the two indicators: economic growth and defense expenditure, we can't prove there was no necessary link between them.

There were a few research literatures on relations of defense expenditure and private consumption. Representative of literature such as Lu Geng used conventional regression analysis, concluded that a weak complementary effect existed in China's defense expenditure and the private consumption; Huang Dong used state spatial variable parameter model to conclude that the relationship between China's defense expenditure and private consumption are changing from substitution effect to complementary effect.

In fact, in the traditional study habits most scholars are more concerned about the macro-state of defense expenditure and national economy (as reflected in the economic growth of GDP, GNP or GNI indicators) interaction, while ignoring the relationship changes in defense expenditure and private consumption, ignoring the micro-state impact of individual consumption. I believed that was not comprehensive, not the system, so its conclusions had some limitations. Thus, this paper attempted unstructured modeling thought, weakening typical economic theory with variables, strengthening statistical properties of feature information, established a unstructured VAR model to study the relationship of three.

\section{Date Processing and Inspection}

The sample cross-section data were chosen from 1978 to 2014, from the National Bureau of Statistics official website. Defense expenditure, economic growth and private consumption were described by defense spending (GFF), gross domestic product (GDP) and per capita consumption level (XFSP) in proper order.

\subsection{Logarithm of Data Processing}

Considered the magnitude of the difference data GFF, GDP and XFSP, logarithm processing didn't change the original sequence characteristics and cointegration relations, enabled the sequences of linear trend and smoothing, eliminated heteroscedasticity and autocorrelation disturbance, so took logarithm processing. In this paper, we got natural logarithm, logarithmic sequences were $\ln$ gff , $\ln g d p$ and $\ln x f s p$.

\subsection{Data Stationary Test}

According to the image observation results in figure 1, we initially determined that these three sequences are not stationary series, each sequence showed a stable growth trend over time.

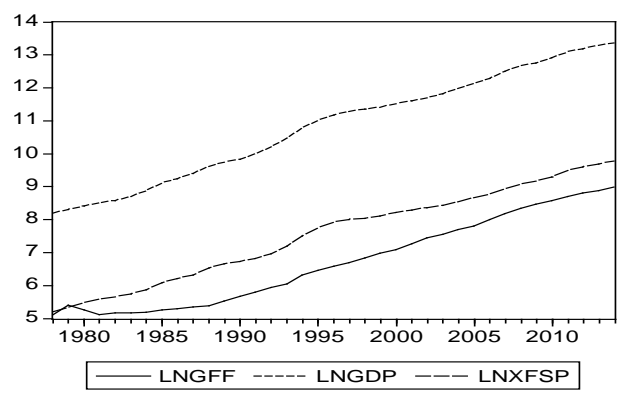

Fig.1 logarithm sequences chart

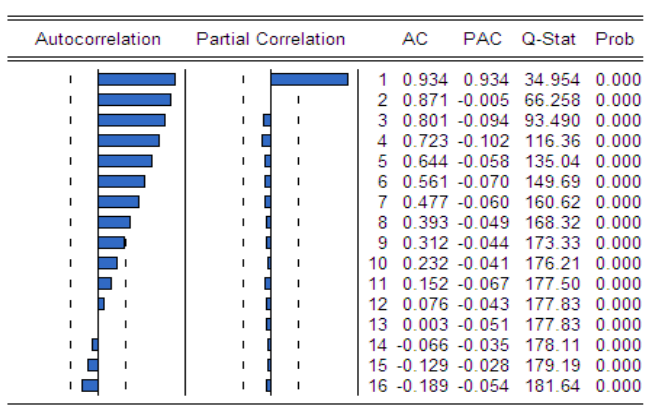

Fig.2 ln gff autocorrelation function chart

In figure 2, sequence ln gff didn't fall into random intervals until 8th period, not approach zero rapidly. In this case, $Q=168.32$, the probability value $p$ is clearly less than $5 \%$ significance level, thus further confirmation is not stable. Analyzing $\ln g d p$ and $\ln x f s p$ could get similar conclusions.

Finally, gave ADF unit root test result in table 1. ADF unit root test was extension from the DF test, for the autocorrelation in first-order difference sequence random error term of observed sequence. The general expression was

$$
\Delta y_{t}=\mu+\beta t+\delta y_{t-1}+\sum_{j=1}^{P} \lambda_{j} \Delta y_{t-j}+u_{t}
$$


There was $p=1,2,3$ or determined by experiment. In expression (1), $\mu$ and $\beta$ represented the constant term and time trend coefficient, according to needs advisable zero value. Observed three sequence and the first difference, second difference sequence of them until stationary series so far, testing ends.

Table. 1 conclusion of ADF unit root test

\begin{tabular}{cccccccc}
\hline Sequence & $\begin{array}{c}\text { Test } \\
\text { form }\end{array}$ & $\begin{array}{c}\text { ADF } \\
\text { value }\end{array}$ & $\begin{array}{c}1 \% \text { critical } \\
\text { value }\end{array}$ & $\begin{array}{c}5 \% \text { critical } \\
\text { value }\end{array}$ & $\begin{array}{c}10 \% \text { critical } \\
\text { value }\end{array}$ & $p$-value & Conclusion \\
\hline $\ln g f f$ & $(c, t, 0)$ & 2.037 & -3.627 & -2.946 & -2.612 & 0.9998 & unstable \\
$\Delta^{2} \ln g f f$ & $(0,0,0)$ & -10.606 & -2.635 & -1.951 & -1.611 & 0.0000 & stable \\
$\ln g d p$ & $(c, t, 4)$ & -0.953 & -4.273 & -3.558 & -3.212 & 0.9368 & unstable \\
$\Delta^{2} \ln g d p$ & $(0,0,3)$ & -3.902 & -2.642 & -1.952 & -1.610 & 0.0003 & stable \\
$\ln x f s p$ & $(c, t, 1)$ & -2.545 & -4.244 & -3.544 & -3.205 & 0.3061 & unstable \\
$\Delta^{2} \ln x f s p$ & $(0,0,1)$ & -5.386 & -2.637 & -1.951 & -1.611 & 0.0000 & stable \\
\hline
\end{tabular}

In table 1, we took SC guidelines to determine the lag length. For example $\ln g d p$, according to the SC guidelines, optimal lag order is 4 , with a non-zero intercept and trend items, test form was $(c, t, 4)$. It found that in the test level of $1 \%$ critical value, null hypothesis $\Delta^{2} \ln$ gff containing the unit root was rejected, thus the sequence was stable, the original sequence was a second order single sequence, marked $\ln g f f \sim I(2)$.Similarly, $\Delta^{2} \ln g d p$ and $\Delta^{2} \ln x f s p$ were stationary series, $\ln g d p$ and $\ln x f s p$ were also second order single sequences, marked $\ln g d p \sim I(2)$ and $\ln x f s p \sim I(2)$.

\subsection{Johansen Cointegration Test}

Table. 2 conclusion of Johansen test

\begin{tabular}{ccccccc}
\hline $\begin{array}{c}\text { Null } \\
\text { hypothesis }\end{array}$ & $\begin{array}{c}\text { Eigenvalu } \\
\text { e }\end{array}$ & $\begin{array}{c}\text { Trace } \\
\text { value }\end{array}$ & $\begin{array}{c}1 \% \text { critical } \\
\text { value }\end{array}$ & e-g value & $\begin{array}{c}1 \% \text { critical } \\
\text { value }\end{array}$ & Lag length \\
\hline None & 0.575998 & 44.41852 & 35.65 & 29.17256 & 25.52 & 3 \\
At most 1 & 0.323171 & 15.24596 & 20.04 & 13.27146 & 18.63 & 3 \\
At most 2 & 0.056419 & 1.974500 & 6.65 & 1.974500 & 6.65 & 3 \\
\hline
\end{tabular}

In table 2, according to trace-statistics test results, the null hypothesis "None" mean "the existence of zero cointegration relationship", because at this time trace statistics was equal to $44.41852,1 \%$ critical value equal to $35.65 \%$, thus trace statistical value was greater than the critical value, rejected the null hypothesis in the first column, which indicated that there was among $\ln$ gff , $\ln g d p$ and $\ln x f s p$ at least one cointegration relationship. Consideration of the null hypothesis "At most 1" indicates "showed at most one cointegration relationship", clearly $15.24596<20.04$, indicating that the null hypothesis can't be rejected, and therefore the following conclusions, there must be a cointegration relationship under 1\% significant level test among the three sequences. E-g statistics test showed same results, the conclusion was consistent.

\subsection{Granger Causality Test}

Granger causality test substance was to reflect on whether there was a time causal relationship between the different sequences. Generally, Granger causality test requires estimation of the following regression expression:

$$
y_{t}=\sum_{i=1}^{q} \alpha_{i} x_{t-i}+\sum_{j=1}^{q} \beta_{j} x_{t-j}+u_{t}
$$

There $u_{t}$ was white noise. null hypothesis of Granger test $H_{0}: \alpha_{1}=\alpha_{2}=\cdots=\alpha_{q}=0$ If the test results significantly non-zero, then reject the null hypothesis.

In Table 3, when the lag lengths were 2-3, $\ln g d p, \ln x f s p$ were the Granger reason of $\ln g f f$ at $1 \%$ significant level. When the lag lengths were $4, \ln g d p, \ln x f s p$ were the Granger reason of $\ln g f f$ at $10 \%$ significant level. No matter what thelag length value was, ln gff is neither the Granger reason of $\ln g d p$ nor $\ln x f s p$. Based on the results, we concluded there was Granger reason 
from $\ln g d p, \ln x f s p$ to $\ln g f f$,but not Granger reason from $\ln g f f$ to $\ln g d p, \ln x f s p$.This showed that economic growth could promote the growth of defense expenditure, raise the level of private consumption also have some positive effects in promoting defense expenditure. The effects time lasted about three periods, while defense expenditure is not direct reason to economic growth and raising the level of private consumption, the impact for the two was not significant.

Table.3 conclusion of Granger causality test

\begin{tabular}{ccccc}
\hline Null hypothesis & Lag length & F-value & p-value & Conclusion \\
\hline LNGDP does not Granger Cause LNGFF & 2 & 28.7815 & $1.1 \mathrm{E}-07$ & reject \\
LNGFF does not Granger Cause LNGDP & 2 & 0.19840 & 0.82111 & accept \\
LNGDP does not Granger Cause LNGFF & 3 & 6.60863 & 0.00171 & reject \\
LNGFF does not Granger Cause LNGDP & 3 & 0.88187 & 0.46285 & accept \\
LNGDP does not Granger Cause LNGFF & 4 & 2.42389 & 0.07591 & reject \\
LNGFF does not Granger Cause LNGDP & 4 & 2.16481 & 0.10371 & accept \\
LNXFSP does not Granger Cause LNGFF & 2 & 23.6804 & $6.7 \mathrm{E}-07$ & reject \\
LNGFF does not Granger Cause LNXFSP & 2 & 0.53566 & 0.59078 & accept \\
LNXFSP does not Granger Cause LNGFF & 3 & 5.46850 & 0.00455 & reject \\
LNGFF does not Granger Cause LNXFSP & 3 & 0.83600 & 0.48592 & accept \\
LNXFSP does not Granger Cause LNGFF & 4 & 2.21718 & 0.09734 & reject \\
LNGFF does not Granger Cause LNXFSP & 4 & 1.11522 & 0.37245 & accept \\
\hline
\end{tabular}

\section{Unconstrained VAR model and analysis}

On macroeconomic analysis, defense expenditure is affected by the interaction of many uncertainties, with variable complex mechanism between economic growth and private consumption, so that the model estimation and inference became very difficult, only rely on existing Economic theory was difficult to completely infer the correct structure of the model. The method of solving this problem was usually the direct use of the statistical nature of the data, constructed unstructured VAR model. the general form of VAR model:

$$
Y_{t}=A_{1} Y_{t-1}+A_{2} Y_{t-2}+\cdots+A_{p} Y_{t-p}+B_{0} X_{t}+\cdots+B_{r} X_{t-r}+\varepsilon_{t}, t=1,2, \ldots, n
$$

Here, $\quad Y_{t-i}=\left[\begin{array}{lll}\ln g f f & \ln g d p & \ln x f s p\end{array}\right]_{t-i}^{T},(i=1,2, \ldots, p)$ represented 3-dimensional endogenous variables and lagged endogenous variable 3 -dimensional vector by $\ln g f f, \ln g d p, \ln x f s p, A_{i}$ formed as a $3 \times 3$-dimensional matrix of parameters to be estimated, according to the AIC and SC criteria, here $p=2$.According to the parameter estimates unconstrained VAR model, and most of the parameter estimates t test statistic significant. According to the output result, unconstrained VAR model estimation results were:

$$
\left[\begin{array}{l}
\ln \text { gff } \\
\ln g d p \\
\ln x f s p
\end{array}\right]_{t}\left[\begin{array}{l}
-0.595 \\
-0.865 \\
-1.002
\end{array}\right]+\left[\begin{array}{ccc}
0.799 & 0.813 & -0.617 \\
-0.042 & 2.545 & -1.327 \\
-0.035 & 1.203 & 0.173
\end{array}\right]\left[\begin{array}{l}
\ln \text { gff } \\
\ln g d p \\
\ln x f s p
\end{array}\right]_{t-1}+\left[\begin{array}{ccc}
0.032 & -0.635 & 0.601 \\
-0.005 & -1.05 & 0.786 \\
0.005 & -0.661 & 0.217
\end{array}\right]\left[\begin{array}{l}
\ln g f f \\
\ln g d p \\
\ln x f s p
\end{array}\right]_{t-2}+\left[\begin{array}{l}
\varepsilon_{1} \\
\varepsilon_{2} \\
\varepsilon_{3}
\end{array}\right]_{t}
$$

\subsection{Model Stability Test}

Figure 3 showed that all the roots' reciprocal module in VAR model were located inside the unit circle, proved VAR model was stable. Observing VAR model, the main factors affecting GFF of $t$ period were GFF of $t-1, t-2$ period, GDP and XFSP factors, and the impact of GDP and XFSP for the same period of defense expenditure was opposite. We also got conclusion that defense expenditure was clearly for the same period the GDP and XFSP was much smaller than the impact of factors affecting their own, even negligible. 


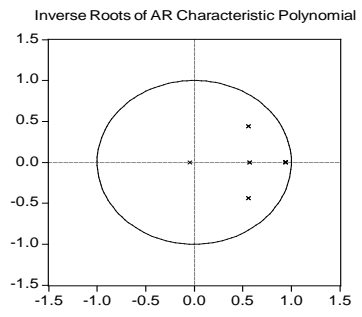

Fig.3 unit circle test

Table.4 VAR model residual coefficient

\begin{tabular}{cccc}
\hline & LNGFF & LNGDP & LNXFSP \\
\hline LNGFF & 1 & 0.1760 & -0.0330 \\
LNGDP & 0.1760 & 1 & 0.7879 \\
LNXFSP & -0.0330 & 0.7879 & 1 \\
\hline
\end{tabular}

\subsection{Impulse Response Function}

Impulse response function was usually used to studying the dynamic characteristics of VAR model focuses on the extent of the reaction of individual endogenous variables on their own and other variables disturbances. VAR model residuals coefficient matrix was given in Table 4, showing the residual correlation between the ln gff equation and the other two equations is weak, the correlation between $\ln g d p$ and $\ln x f s p$ equations and strong, so chose $\ln g f f$ equation for the appropriate analysis object.

Response to Generalized One S.D. Innovations \pm 2 S.E.
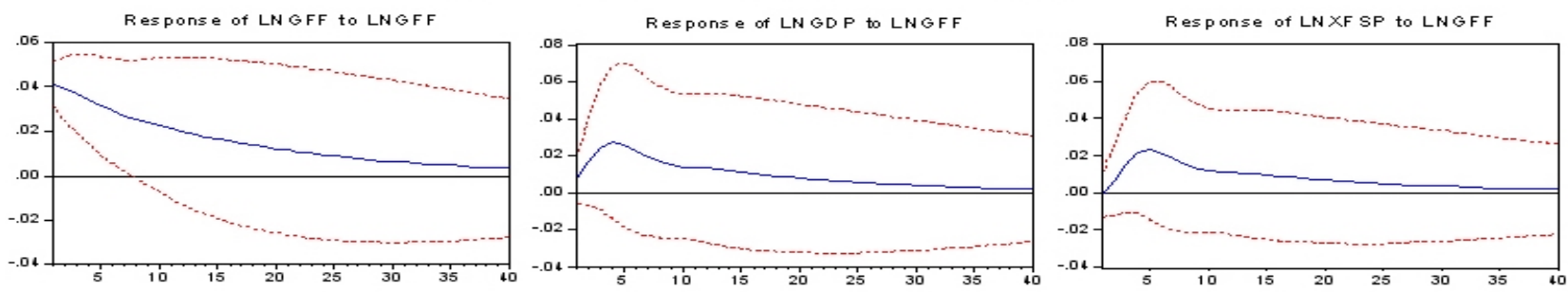

Fig.4 impulse response of endogenous variable to ln gff disturbance

Impulse response function was used to measuring a pulse within the random disturbance of endogenous variables $\ln$ gff , for the impact of current and future value of $\ln g f f, \ln g d p$ and $\ln x f s p$. Select the Cholesky factor as a standard deviation innovation pulses, pulse from the equation, the pulse order of the followed by $\ln g f f, \ln g d p$ and $\ln x f s p$, then observed pulse response effect in Figure 4. In gff make an immediate response to the standard deviation of its own innovation impulse, the result was positive and after 40 cycles of slow decay stability tends from maximum to zero, indicating that for their own defense expenditure had a more lasting effect of the strong positive; the impact of the response to $\ln g d p$ was positive and in the 4th period reached maximum, indicating that for economic growth defense expenditure had a weak positive effect. For $\ln x f s p$, lagged impact of the emergence of a response to the results, the response was positive and in the 5th period reached maximum , indicating that the same defense expenditure lags weak positive effect for the consumer.

\section{Conclusions and Suggestions}

\subsection{Economic growth and private consumption growth contributed to enhance the level of defense expenditure}

Granger causality test showed that economic growth, private consumption were the cause of defense expenditure, changes in economic growth and private consumption can lead to significant changes in defense expenditure. Impulse response function results showed that this effect was related 
to the strong positive effect and sustained long-term impact on defense expenditure. In fact, China in recent years, rapid and stable economic development provided a strong economic support to national defense construction. Improving the level of consumer purchasing power means to enhance the standard of living improved, the inevitable desired to have a safe and stable living environment, would pay more attention to the development of national defense construction. Suggested to form a stable linkage mechanism for defense expenditure, economic growth and private consumption to ensure that the level of defense expenditure adapt to economy growth.

\subsection{Enhance the level of defense expenditure will not lead to economic slowdown and lower private consumption levels}

Granger causality test pointed out that economic growth and private consumption growth were not due to defense expenditure. This suggested that an increase in defense expenditure can't lead to economic slowdown nor inevitably damage the national economy running smoothly. Defense expenditure on private consumption did not have a "crowding out" effect; an appropriate increase in the level of defense expenditure didn't decrease people's quality of life. In recent years, although China's defense expenditure was growing, but compared with the US and European countries, defense expenditure accounted for the proportion of total GDP was still low, per capita defense expenditure was clearly insufficient. It recommended related departments to strengthen feasibility studies, without affecting the economic performance of the premise of an appropriate increase in the level of defense expenditure, accelerated the pace of national defense.

\subsection{Strengthen civil-military integration and play its role in boosting defense expenditure for economic growth}

VAR model shows that defense expenditure made a weak positive correlation effect on economic growth and private consumption, with 4-5 year lag. This showed that China's defense expenditure is not enough to promote the national economy as a positive and effective role at this stage. The relevance of national defense and economic development was not strong, "spillover effect" national defense feeding national economy had not been revealed. Recommended the strengthening of civil-military integration, integrating the armed forces, the full use of their advantages in the civilian sector of the development of military high technology, enhanced military and civilian sectors complementary advantages, resource sharing, fruit transformation, the establishment of private secret production qualification certification system, improved the integration degree of association, shorten the "spillover effect" lag of national defense construction, growing role in boosting defense spending to economic growth.

\section{References}

[1] Benoit Emile. Growth and Defense in Developing Countries[J]. Economic Development and Cultural Change, Vol. 26(1978) No.2, p. 271 -280.

[2] Halicioglu. Defense spending and economic growth in Turkey: Anempirical application of new macroeconomic theory[J]. Review of Middle East Economics and Finance, Vol.2(2004), p. 193-201.

[3] Lim David. Another look at Growth and Defence in Less Developed Countries[J]. Economic Development and Cultural Change, Vol.31(1983),p. 377-384.

[4] Starr H F W, Hoole J A. Hart, Freeman J R. The relationship between defense spending and inflation[J]. Journal of Conflict Resolution. Vol.28(1984),p.103-22.

[5] Cuaresma J, Reitschuler G. A non-linear defence-growth nexus[J]. Defense and Peace Economics. Vol.15(2003),p. 71-82.

[6] Cappelen, Adne, Nils Petter Gleditsch, Olav Bjerkholt. Military spending and economic growth in the OECD counties[J]. Journal of Peace Research. Vol.21(1984),p. 361-73. 